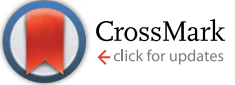

Cite this: RSC Adv., 2017, 7, 11420

\title{
Graphene quantum dot-based theranostic agents for active targeting of breast cancer $\dagger$
}

\begin{abstract}
N. R. Ko, ${ }^{a}$ M. Nafiujjaman, ${ }^{\text {b }}$ J. S. Lee, ${ }^{c}$ H.-N. Lim, ${ }^{a}$ Y.-K. Lee ${ }^{\star b d}$ and I. K. Kwon ${ }^{\star a}$
A novel graphene quantum dot (GQD)-based nanocarrier labeled with Herceptin (HER) and $\beta$-cyclodextrin $(\beta-C D)$ was developed as a promising theranostic candidate for the treatment of breast cancer. Each component of this nanocarrier plays a critical role in providing multiple functions to achieve enhanced anticancer activities. HER provides active targeting to HER2-overexpressed breast cancer to enhance accumulation in the cancer cells. $\beta-C D$ provides a site for loading of a hydrophobic anticancer drug, doxorubicin (DOX), via "host-guest" chemistry. The nanocarriers also provide diagnostic effects due to the blue-color emission of the GQDs. In response to the acidic environment of cancer cells, the GQD-complex degraded rapidly and the DOX was released in a controlled manner to inhibit proliferation of cancer cells. This multi-functional drug delivery system leads to a synergistically enhanced anticancer strategy which provides treatment and diagnosis. The intracellular trafficking results, along with cell viability and confocal laser scanning microscopy, suggest that the GQD-complex offers a viable strategy for HER2-overexpressed breast cancer-targeting drug delivery applications.
\end{abstract}

Received 28th October 2016 Accepted 17th January 2017

DOI: $10.1039 / c 6 r a 25949 a$

rsc.li/rsc-advances

to offer functionality. ${ }^{12,13}$ The formation of hydrogen bonding of amine groups with water molecules improved the colloidal stability of GQD-NH$H_{2}$ and amine groups on the surface of GQDs were utilized to load biomolecules (proteins, antibodies, and nucleic acids), and anticancer drugs via facile coupling reactions. This unique property enables GQD- $\mathrm{NH}_{2}$ to be used as a potential imaging agent and a drug delivery carrier for treatment of breast cancer.

Breast cancer is the most common female invasive cancer worldwide and its occurrence rates are rapidly increasing..$^{14}$ It is known that the survival rates for breast cancer decrease as cancer develops. Patients with early-stage cancer can have more treatment options..$^{15}$ Therefore, early diagnosis has become important to reduce the mortality of breast cancer and broaden treatment options. The main breast cancer treatments are surgery, radiation therapy, chemotherapy, and hormone therapy. However, these current methods have severe side effects including longterm sequelae, lymphedema, and hair loss. ${ }^{16-18}$ Recently, targeted therapy has been identified as one of the more advanced approaches for the treatment of cancer due to its enhanced anticancer activity with reduction of side effects. ${ }^{19}$ About $34 \%$ of total patients have HER2 (Human Epidermal growth factor Receptor 2)-positive breast cancer. ${ }^{20}$ Abnormally amplified HER2 genes in breast cells overexpress HER2 on the surface of breast cells, leading to uncontrolled cell growth and division. ${ }^{20}$ Herceptin (HER), an FDA-approved monoclonal antibody specifically designed for anti-proliferation of HER $2,{ }^{21}$ is one of the advanced approaches to target HER2-overexpressed breast cancer. ${ }^{22}$ Binding of HER to HER2 can not only inhibit intracellular signaling, but also induce immune response, resulting in 


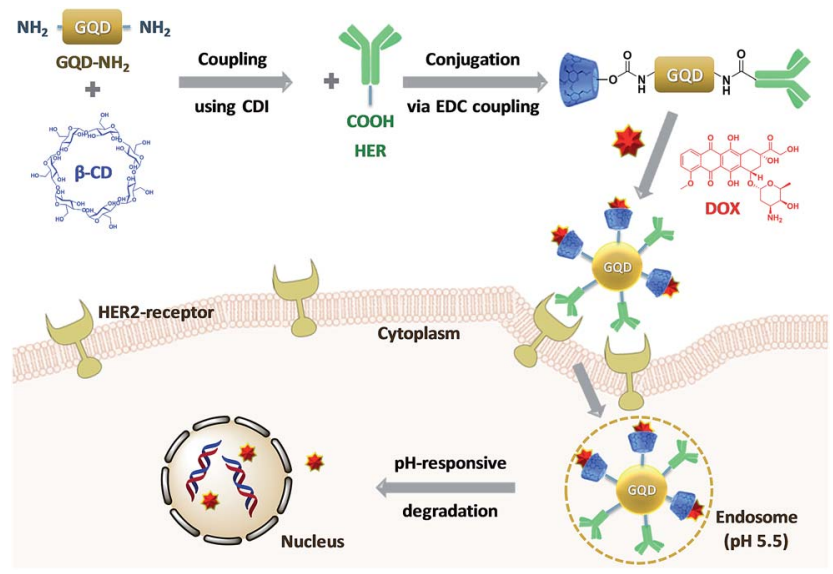

Scheme 1 Preparation of DOX-loaded HER-labeled GQD-based nanocarriers and its drug release via cellular uptake for active targeting of breast cancer cells.

a cellular apoptosis. ${ }^{23,24}$ Despite these advances, HER has a major challenge. It has very low antitumor efficiency. Many clinical trials showed that a combination of HER treatment with chemotherapy can enhance anticancer activity. ${ }^{25}$

HER-labeled GQD-based nanocarriers were designed for diagnosis and treatment of HER2-overexpressed breast cancer (Scheme 1). The blue-color emitted by GQDs can be used to detect the location of a tumor in the body. This photoluminescence is important to improve survival rates of breast cancer patients by providing for early diagnosis. The GQDs were loaded with HER and a model anticancer drug doxorubicin (DOX) in order to provide for treatment of HER2-positive breast cancer. HER allows for selective targeting of nanocarriers to HER2-overexpressing cells, leading to effective accumulation in the cancer cells with limited exposure towards normal tissues. The accumulated nanocarriers enable for the diagnosis of cancer using the optical properties of the GQDs which present a blue-color emission. Simultaneously, these nanocarriers release DOX to inhibit proliferation of cancer cells. This multi-functional drug delivery system leads to a synergistically enhanced anticancer activity.

\section{Experimental section}

\subsection{Materials}

L-Glutamic acid (99\%) was purchased from Sumchun Pure Chemical Co. Ltd (South Korea). 1,1'-Carbonyldiimidazole (CDI, $>97 \%$ ), 1-ethyl-3-(3-dimethylaminopropyl)-carbodiimide (EDC, $>97 \%$ ), 4-dimethylaminopyridine (DMAP, >98\%), N-hydroxysuccinimide (NHS, 98\%), and doxorubicin hydrochloride (DOX, $-\mathrm{NH}_{3}{ }^{+} \mathrm{Cl}^{-}$salt form, 98.0-102.0\% (HPLC)) were purchase from Aldrich. $\beta$-Cyclodextrin ( $\beta$-CD, $>98 \%$ ) was purchased from TCI. Herceptin was purchased from Roche. RPMI (Roswell Park Memorial Institute) 1640, fetal bovine serum (FBS), Dulbecco's phosphate-buffered saline (DPBS), trypsin-EDTA (TE), and penicillin-streptomycin (PS) were purchased from GIBCO BRL (Invitrogen Co., USA). HEPES (Product \# H4034) and sodium bicarbonate (Product \# S6297) were purchased from Sigma- aldrich. Lysotracker (Product \# L7526) was purchased from Thermo Fisher Scientific. Unless otherwise indicated, reagents were used as received.

\subsection{Instrumentation and analysis}

Fluorescence spectra were collected on a Shimadzu RF-5301PC in the wavelength range of $380-800 \mathrm{~nm}$ and the slit width for both excitation and emission was $5 \mathrm{~nm}$. UV/Vis spectra were collected on Shimadzu UV-1650PC using a $1 \mathrm{~cm}$ wide quartz cuvette. TGA measurements were carried out using a TA Instruments 2960 SDT V3.0F. Typically, aliquots $(2-6 \mathrm{mg})$ of dried GQD-NH $\mathrm{N}_{2}$, GQD- $\beta \mathrm{CD}$, GQD-comp were placed in a platinum pan inside a programmable furnace. The sample was heated from 10 to $800{ }^{\circ} \mathrm{C}$ at a heating rate of $10^{\circ} \mathrm{C} \mathrm{min}^{-1}$ under nitrogen flow. Percentage of weight loss was then calculated. FTIR spectra were recorded on a high tech Thermo Scientific Nicolet 380 spectrometer (USA) using KBr Pellet technique with scanning in the wavenumber range $400-4000 \mathrm{~cm}^{-1}$. The number-average diameter of GQD, GQD-HER, GQD- $\beta C D$, GQDcomp in distilled water was measured by DLS at a fixed scattering angle of $90^{\circ}$ at $25^{\circ} \mathrm{C}$ using a Malvern Instruments Zetasizer Nano S 90 (ZEN1690, UK) equipped with a $633 \mathrm{~nm}$ He-Ne gas laser. TEM images were taken using a field-emission transmission electron microscopy (FE-TEM, JEM-2100F, JEOL, Japan) operated at $200 \mathrm{kV}$. Each TEM sample $\left(0.1 \mathrm{mg} \mathrm{mL}^{-1}\right)$ was placed on a 400 mesh carbon-coated copper grid, blotted and then allowed to air dry at room temperature. The morphology the aqueous dispersions of GQDs- $\mathrm{NH}_{2}$ and GQD-comp at $0.25 \mathrm{mg} \mathrm{mL}^{-1}$ was observed using a JSM-7610F field-emission scanning electron microscope (FE-SEM, JEOL, Japan), operating at an accelerating voltage of $200 \mathrm{kV}$.

\subsection{Synthesis of GQD-NH}

Amine-functionalized GQDs (GQD- $\mathrm{NH}_{2}$ ) were synthesized by pyrolyzing L-glutamic acid using a previously reported method with minor modifications. ${ }^{26}$ Briefly, $2 \mathrm{~g}$ s-glutamic acid was added to a glass bottle and heated to $110{ }^{\circ} \mathrm{C}$ using a heating mantle. The solid L-glutamic acid changed to a liquid, and the boiling colorless liquid turned brown, which indicated the formation of GQD- $\mathrm{NH}_{2}$. Then, $10 \mathrm{~mL}$ water was added to the solution followed by stirring for $30 \mathrm{~min}$. The solution was then cooled to room temperature, centrifuged at $10000 \mathrm{~g}$ for $30 \mathrm{~min}$, and the supernatant was collected and lyophilized.

\subsection{Synthesis of GQD- $\beta C D$}

The purified, dried GQD- $\mathrm{NH}_{2}(500 \mathrm{mg})$ dissolved in PBS $(5 \mathrm{~mL})$ was added drop-wise to a solution of $\beta \mathrm{CD}(3.6 \mathrm{~g}, 3.2 \mathrm{mmol})$ and CDI ( $516.6 \mathrm{mg}, 3.2 \mathrm{mmol})$ in PBS $(5 \mathrm{~mL})$. The resulting mixture was stirred at $50^{\circ} \mathrm{C}$ for 4 days. The solution was filtered and the filtrates were then dialyzed using a dialysis tubing $(\mathrm{MWCO}=$ $1000 \mathrm{~g} \mathrm{~mol}^{-1}$ ) against DW for 2 days to remove residual byproducts. The purified GQD- $\beta$ CD solution was lyophilized and stored at room temperature until further use. Yield $=$ $232.5 \mathrm{mg}$. 


\subsection{Synthesis of $\beta C D-G Q D-H E R$ conjugates (GQD-comp)}

A mixture of GQD- $\beta C D(84.7 \mathrm{mg})$ and DMAP (60 mg, $0.49 \mathrm{mmol}$ ) dissolved in DMSO (5 mL) was added into a solution of HER (127.0 mg, $0.9 \mu \mathrm{mol})$ and EDC (762 mg, $4.9 \mathrm{mmol})$ in DMSO $(5 \mathrm{~mL})$. After stirring for $1 \mathrm{~h}$, NHS $(60 \mathrm{mg}, 0.49 \mathrm{mmol})$ was added and the resulting mixture was then stirred at room temperature for $20 \mathrm{~h}$. This solution was dialyzed using a dialysis tubing $\left(\right.$ MWCO $\left.=1000 \mathrm{~g} \mathrm{~mol}^{-1}\right)$ against DW for 2 days and filtered through $0.45 \mu \mathrm{m}$ filter to remove aggregates. The Bradford assay was conducted according to standard protocol to determine the amount of HER. ${ }^{27}$ The purified GQD-complex solution was lyophilized and stored at $4{ }^{\circ} \mathrm{C}$ until further use. Yield $=89.3 \mathrm{mg}$.

\subsection{Preparation of DOX-loaded GQD-comp (DL-GQD)}

A solution of GQD-comp (50.0 mg), DOX (5 mg), and $\mathrm{Et}_{3} \mathrm{~N}(3.60$ $\mu \mathrm{L}, 3$ molar equivalents to DOX) dissolved in DMSO ( $3 \mathrm{~mL}$ ) was stirred at room temperature. After $2 \mathrm{~h}$, PBS (57 mL) was added drop-wise to the GQD solution and stirred at room temperature for $24 \mathrm{~h}$. The resulting mixture was transferred into a dialysis tubing $\left(\mathrm{MWCO}=1000 \mathrm{~g} \mathrm{~mol}^{-1}\right)$ and dialyzed against DW (2000 $\mathrm{mL}$ ) for $20 \mathrm{~h}$. To determine the loading capacity (LC) and encapsulation efficiency (EE) of DOX, an aliquot of the DL-GQD was mixed with $3 \mathrm{~mL} \mathrm{DMF}$ and its UV/Vis spectra was measured at $\lambda_{\mathrm{ex}}=496 \mathrm{~nm}$. LC and EE of DL-GQD was calculated as follows;

$$
\begin{aligned}
& \mathrm{LC}=\frac{\text { weight of DOX in DL }- \text { GQD }}{\text { total weight of DL }- \text { GQD }} \\
& \mathrm{EE}=\frac{\text { weight of DOX in DL }- \text { GQD }}{\text { initial amount of DOX added }}
\end{aligned}
$$

\section{7. pH-triggered release of DOX from DL-GQD}

$3 \mathrm{~mL}$ DL-GQD solution in $\mathrm{pH} 7 \mathrm{PBS}\left(1 \mathrm{mg} \mathrm{mL}{ }^{-1}\right)$ was placed in a dialysis tubing $\left(\mathrm{MWCO}=1000 \mathrm{~g} \mathrm{~mol}^{-1}\right.$ ) and then dialyzed against $50 \mathrm{~mL}$ PBS buffer ( $\mathrm{pH}$ 5.5). As a control, the same procedure was conducted in $\mathrm{pH} 7.4 \mathrm{PBS}$ buffer. In order to prevent decomposition of DOX during the release experiment, the sample was kept in the dark. At each selected time interval $(2,8,17.5,22.5,28.5 \mathrm{~h}), 1 \mathrm{~mL}$ of dialysate was taken and an equal volume of fresh PBS buffer was replaced. It was diluted with DMF $(1: 3 \mathrm{v} / \mathrm{v})$. The absorbance was measured using a UV/ Vis spectrometer and compared to a standard curve. For quantitative analysis, the equivalent amount of DOX encapsulated in DL-GQD was dissolved in a mixture of PBS and DMF $(1: 3 \mathrm{v} / \mathrm{v})$ and its UV/Vis spectrum was also recorded.

\subsection{Cell culture}

The human breast cancer cell lines, BT-474 and MCF-7, were purchased from Korean Cell Line Bank (KCSB, South Korea). HER2-positive breast cancer cells, BT-474, were cultured in RPMI 1640 with L-glutamine (300 $\mathrm{mg} \mathrm{L}^{-1}$ ) containing 10\% FBS (fetal bovine serum), $1 \%$ antibiotics (50 units per $\mathrm{mL}$ penicillin and 50 units per mL streptomycin), $25 \mathrm{mM}$ HEPES, and $25 \mathrm{mM}$
$\mathrm{NaHCO}_{3}$ at $37{ }^{\circ} \mathrm{C}$ in a humidified atmosphere containing 5\% $\mathrm{CO}_{2}$. HER2-negative breast cancer cells, MCF-7, were cultured in RPMI 1640 with L-glutamine $\left(300 \mathrm{mg} \mathrm{L}^{-1}\right)$ containing $10 \% \mathrm{FBS}$, $1 \%$ antibiotics (50 units per $\mathrm{mL}$ penicillin and 50 units per $\mathrm{mL}$ streptomycin) at $37{ }^{\circ} \mathrm{C}$ in a humidified atmosphere containing $5 \% \mathrm{CO}_{2}$.

\subsection{Cell viability using CCK-8 assay}

MCF-7 cells were plated at a density of $5 \times 10^{3}$ cells per well into a 96-well plate and incubated for $18 \mathrm{~h}$ in RPMI $(100 \mu \mathrm{L})$ containing $10 \%$ FBS and $1 \%$ antibiotics. BT- 474 cells were plated at $3 \times 10^{4}$ cells per well into a 96-well plate and incubated for $72 \mathrm{~h}$ in RPMI $(100 \mu \mathrm{L})$ containing $25 \mathrm{mM}$ HEPES, $25 \mathrm{mM} \mathrm{NaHCO}_{3}$, $10 \%$ FBS, and $1 \%$ antibiotics. Note that BT- 474 cells have a doubling time of approximately $100 \mathrm{~h}$, whereas MCF-7 cells double every $29 \mathrm{~h}^{.28,29}$ After incubation, a solution of GQDcomp, DL-GQD, and free DOX in PBS at different concentrations were treated and incubated at $37^{\circ} \mathrm{C}$. After $48 \mathrm{~h}, 100 \mu \mathrm{L}$ of CCK solution was added into each well and the plate was incubated for $2 \mathrm{~h}$. The absorbance was measured at $450 \mathrm{~nm}$ using a Benchmark Plus microplate spectrophotometer (Biorad, BR170-6930).

\subsection{Confocal laser scanning microscopy (CLSM)}

A total of $5 \times 10^{3}$ BT- 474 cells per well were seeded into a 6-well plate and incubated at $37{ }^{\circ} \mathrm{C}$ for $72 \mathrm{~h}$. They were then treated with $10 \mu \mathrm{g} \mathrm{mL}^{-1}$ DL-GQD in PBS and $2 \mu \mathrm{M}$ LysoTracker Green DND-26 at $37^{\circ} \mathrm{C}$ for $14 \mathrm{~h}$. The wells were washed with PBS three times to remove the free particles. After the removal of supernatant, the cells were fixed with $4 \%$ formaldehyde solution at room temperature for $20 \mathrm{~min}$. The images were obtained by confocal laser scanning microscope (CLSM, Nikon C1Si, Japan).

\section{Results and discussion}

\subsection{Synthesis of GQD- $\mathrm{NH}_{2}$ and GQD-comp}

Scheme 2 illustrates our approach to synthesize well-defined GQD-based nanocarriers consisting of $\beta$-CD and HER on the surface (GQD-comp).

First, blue-color emitting GQD- $\mathrm{NH}_{2}$ were synthesized using a bottom-up method. The main advantage of this method is that a natural L-glutamic acid was used as a precursor, based on a previous method with some modifications. ${ }^{26}$ In fact, many researchers have struggled to optimize the synthetic method of GQDs. Generally, GQDs are synthesized by condensation of

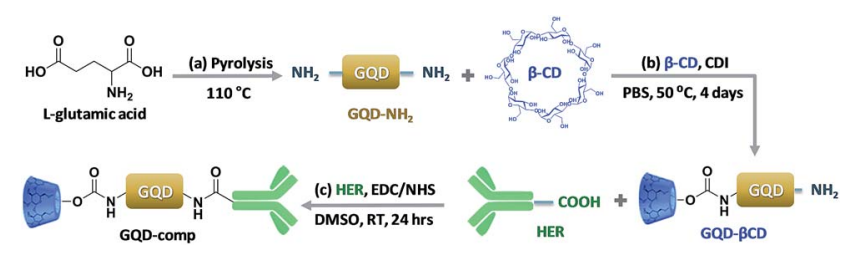

Scheme 2 Synthetic route to a GQD-comp in three steps: pyrolysis of L-glutamic acid (a), CDI coupling with $\beta-C D(b)$, and EDC/NHS coupling in the presence of HER (c). 
aromatic compounds in a liquid phase, which is known to be a cumbersome technique that is difficult to purify. ${ }^{30}$ GQDs can also be prepared from carbon fiber using a mixture of sulfuric acid and nitric acid to breakdown the planar structure of graphene. ${ }^{31}$ However, this alternate conventional methods still has the same drawbacks as mentioned earlier. To circumvent the limitations of the previous methods, a new method to generate GQDs from various organic molecules, including citric acid ${ }^{32}$ and glucose ${ }^{33}$ was developed. These precursors are biocompatible, cheap, and commercially available. Among these molecules, we have found that L-glutamic acid is the best precursor for the synthesis of well-defined GQD- $\mathrm{NH}_{2}$. Using rhodamine $\mathrm{B}$ as a reference, the quantum yield of the GQD- $\mathrm{NH}_{2}$ was determined to be $24 \%$, which is significantly enhanced as compared to previous reports. ${ }^{31}$

Amine groups on the surface of the GQD- $\mathrm{NH}_{2}$ were further utilized to conjugate to the hydroxyl groups of $\beta$-CD via a facile CDI coupling reaction. $\beta-C D$, a type of cyclic oligosaccharide, can work as a drug pocket for delivery of hydrophobic drugs due to its hydrophobic cavity and hydrophilic surface. ${ }^{34}$ Partially grafted $\beta$-CD on the surface of the GQD can not only enhance the water dispersity of the GQDs, but also solubilize the hydrophobic DOX via host-guest chemistry. The purified GQD$\beta C D$ was then used to synthesize GQD-comp via an EDC/NHS coupling reaction in the presence of HER. A carboxylic acid group of HER can form an amide bond with one of the amine groups of GQDs, resulting in successful grafting of HER on the surface of the GQDs. Both ester and amide bonds between $\beta$-CD/HER and GQDs were cleaved in response to the acidic environment of breast cancer cells, leading to a rapid and controlled release of DOX.

\subsection{Characterization of GQD-NH $\mathrm{NH}_{2}$ and GQD-comp}

Well-designed GQD- $\mathrm{NH}_{2}$ and GQD-comp were characterized using UV/Vis, fluorescence spectroscopy, TGA, and FTIR (Fig. 1). First, UV/Vis spectroscopy was conducted to confirm the a)

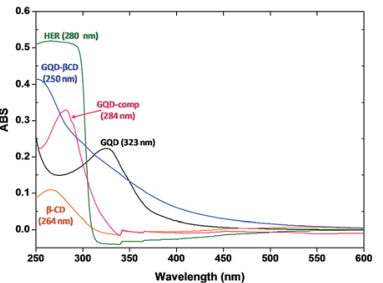

c)

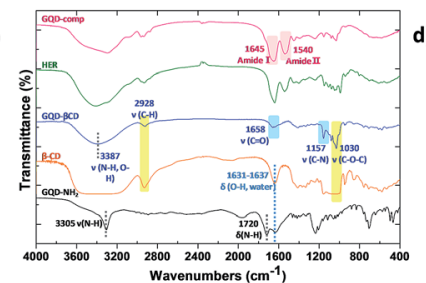

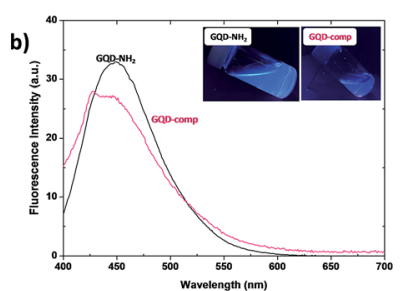

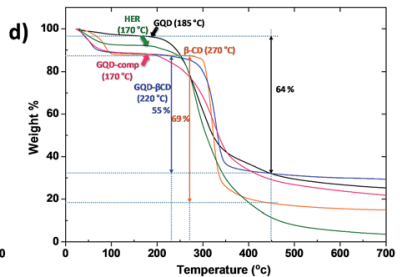

Fig. 1 Characterization of GQD-NH$H_{2}, \mathrm{GQD}-\beta C D$, and GQD-comp using UV/Vis spectroscopy (a), fluorescence spectroscopy (b), FTIR (c), and TGA (d). Blue-color emission of GQD-NH $\mathrm{N}_{2}$ and GQD-comp were observed under the UV lamp (365 $\mathrm{nm}$ ) (b, inset). successful surface modification of GQD-NH $\mathrm{N}_{2}$ with $\beta$-CD and HER (Fig. 1a). A broad peak at $323 \mathrm{~nm}$ indicates the major uniform size of the $\mathrm{sp}^{2}$ clusters in the GQD- $\mathrm{NH}_{2}$ even though these $\mathrm{sp}^{2}$ clusters were doped in the $\mathrm{sp}^{3}$ matrix. ${ }^{33}$ The maximum absorption of GQD- $\beta C D$ showed a blue-shift $(250 \mathrm{~nm})$ after conjugation with $\beta$-CD $(264 \mathrm{~nm})$. After the EDC/NHS coupling reaction with HER, the peak of GQD-comp was shifted toward a longer wavelength $(284 \mathrm{~nm})$, corresponding to the absorption peak of free HER (280 nm). This red-shift of the maximum absorption of GQD-comp indicated the successful conjugation of GQD- $\beta C D$ and HER.

The blue-color emission properties of GQD-NH $\mathrm{H}_{2}$ and GQDcomp were evaluated using fluorescence spectroscopy (Fig. 1b). When the GQD- $\mathrm{NH}_{2}$ solution was excited at $370 \mathrm{~nm}$, the emission peak at $450 \mathrm{~nm}$, which is in blue light range, was observed. In addition, the emission peak of GQD- $\mathrm{NH}_{2}$ was shifted to redcolor emission region as tuning the excitation wavelength from $300 \mathrm{~nm}$ to $510 \mathrm{~nm}$ (Fig. S2 $\dagger$ ). This blue-color emission and tunable fluorescence properties not only provide a good cell penetration property for deep tissue imaging, but exhibit low cytotoxicity, which is important for bio-imaging applications. ${ }^{26,35-37}$ A similar result was obtained from the GQD-comp under the same condition. A strong blue light was also observed when the GQD- $\mathrm{NH}_{2}$ and GQD-comp solutions were exposed under an UV lamp at $365 \mathrm{~nm}$ (Fig. 1b (inset)). Such excellent photoluminescence property can be attributed to a large stokes shift $(450 \mathrm{~nm}$ emission $-370 \mathrm{~nm}$ excitation $=80$ $\mathrm{nm}$ ) which enables the GQD-comp to detect tumors as an optical probe for bio-imaging applications. The continued existence of GQDs in GQD-comp was easily confirmed by observation of blue color after surface modifications with $\beta$-CD and HER.

Chemical bonds on the surface of GQD- $\mathrm{NH}_{2}, \mathrm{GQD}-\beta \mathrm{CD}$, and GQD-comp were characterized using FTIR (Fig. 1c). Two peaks observed at 3305 and $1720 \mathrm{~cm}^{-1}$ in the spectrum of GQD-NH corresponds to $\mathrm{N}-\mathrm{H}$ bonds, indicating that the prepared GQDs$\mathrm{NH}_{2}$ is rich in $\mathrm{NH}_{2}$ groups. ${ }^{38}$ These peaks also suggest that the GQDs- $\mathrm{NH}_{2}$ is hydrophilic with enhanced colloidal stability in water. ${ }^{39}$ An energy dispersive X-ray spectroscopy was conducted to quantify the amount of $\mathrm{N}$ in the GQDs-NH $\mathrm{N}_{2}$ (Fig. S1 $\dagger$ ). GQD$\beta C D$ possessed three new peaks at 3387,1658 , and $1157 \mathrm{~cm}^{-1}$ corresponding to $\nu(\mathrm{N}-\mathrm{H}$ or $\mathrm{O}-\mathrm{H}), \nu(\mathrm{C}=\mathrm{O})$, and $\nu(\mathrm{C}-\mathrm{N})$, as well as two peaks at 2928 and $1030 \mathrm{~cm}^{-1}$ corresponding to $\nu(\mathrm{C}-\mathrm{H}), \nu(\mathrm{C}-$ $\mathrm{O}-\mathrm{C})$ of $\beta$-CD. ${ }^{40}$ After conjugation with HER, GQD-comp has two new peaks at 1645 and $1542 \mathrm{~cm}^{-1}$ respectively assigned to amide I (-CO-NH-) and amide II (-CO-NH-) bonds. These results indicate the successful immobilization of HER on the surface of GQD- $\mathrm{NH}_{2} \cdot{ }^{41,42}$

Thermal properties of GQD-NH $\mathrm{N}_{2}, \mathrm{GQD}-\beta \mathrm{CD}$, and GQD-comp were examined using TGA and their results are shown in Fig. 1d. GQD- $\mathrm{NH}_{2}$ showed a significant decrease in weight between 185 and $450{ }^{\circ} \mathrm{C}$, with a $64 \%$ weight loss. After conjugation with $\beta$ $\mathrm{CD}$, GQD- $\beta C D$ started to degrade at $220{ }^{\circ} \mathrm{C}$ with a $55 \%$ weight loss up to $450^{\circ} \mathrm{C}$. This result indicates that not only the thermal stability of GQD- $\beta C D$ was improved by conjugation with $\beta$-CD but also the content of $\beta$-CD grafted on the surface of GQDs was calculated to be $55 \mathrm{wt} \% .^{43} \mathrm{GQD}$-comp shows a two-step degradation. The first weight loss of approximately $11 \%$ indicates the 

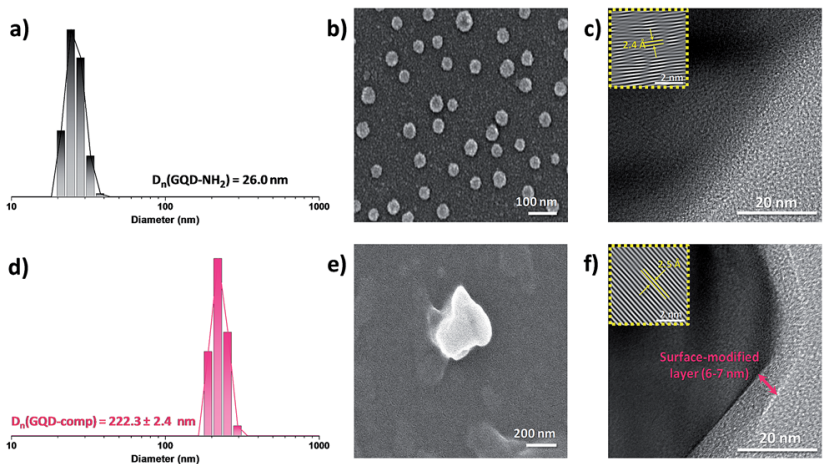

Fig. 2 DLS diagrams, FE-SEM, and FE-TEM images of GQD-NH 2 (a-c) and GQD-comp (d-f). Pre-dried samples were dispersed in DW at $0.1 \mathrm{mg} \mathrm{mL}^{-1}$ (for DLS and TEM) and $0.25 \mathrm{mg} \mathrm{mL}^{-1}$ (for SEM). The insets show low-magnification (top) and FFT filtered TEM images (bottom).

loss of water molecules up to $100{ }^{\circ} \mathrm{C}$. The second major weight loss started at $170{ }^{\circ} \mathrm{C}$, which is lower than GQD- $\beta C D$. This corresponds to the degradation of free $\operatorname{HER}\left(170^{\circ} \mathrm{C}\right)$. This result indicates that HER was successfully conjugated with GQD- $\beta C D$.

The size and morphology of GQD- $\mathrm{NH}_{2}$ and GQD-comp particles were examined using DLS, FE-SEM, and FE-TEM. The DLS (Fig. 2a and d) and SEM results (Fig. 2b and e) indicate that the particle size of GQD-comp was significantly increased (222 $\mathrm{nm}$ ) after surface modification of GQD- $\mathrm{NH}_{2}$ (26 $\mathrm{nm})$. This size is in the optimal size range for nanoparticles used as drug carriers. ${ }^{44}$ The TEM image of GQD-comp in Fig. $2 f$ displays the thickness of the surface modification layer $(\beta-C D$ and HER) which was determined to be 6-7 $\mathrm{nm}$. In addition, the lattice spacing of GQD-comp was determined to be $2.5 \AA$ which is comparable to that of GQD- $\mathrm{NH}_{2}$ (Fig. 2c). This indicates that the GQDs maintained their stability after surface modifications.

\subsection{In vitro cytotoxicity and selective targeting of GQD-comp}

Biocompatibility and active targeting efficiency are important properties of cancer-targeting drug carriers for enhanced anticancer efficacy and reduced side effects. It is known that the HER2 level is found around 20000 per cell in normal breast cells and it is over 100 times more common in HER2-overexpressed breast cancer cells. ${ }^{45}$ This significant variation in HER2 level has promoted the development of HER-containing drug carriers for the treatment of breast cancer cells. ${ }^{46,47}$ Fig. 3 shows the cell viability of MCF-7 and BT-474 cells in the presence of GQD-comp at different concentration $\left(0,20,100,200,300,500 \mu \mathrm{g} \mathrm{mL}{ }^{-1}\right)$. MCF-7 and BT-474 are HER2-negative and positive breast cancer cell lines, respectively. Cells were incubated with GQD-comp for $48 \mathrm{~h}$ and their viabilities were evaluated using CCK-8 assay. The viability of MCF-7 was $>95 \%$ up to $500 \mu \mathrm{g} \mathrm{mL}{ }^{-1}$ indicating low cytotoxicity of GQD-comp, whereas the viability of BT-474 gradually decreased with increasing concentration of GQD-comp. Interestingly, the cell viability difference between MCF-7 and BT-474 cells increased as the amount of GQD-comp increases. For example, the viability of BT-474 was lower than MCF-7 at 20 $\mu \mathrm{g} \mathrm{mL} \mathrm{m}^{-1}(<5 \%)$ and it became $>35 \%$ when the concentration of GQD-comp elevated at $500 \mu \mathrm{g} \mathrm{mL} \mathrm{m}^{-1}$. This indicates an excellent

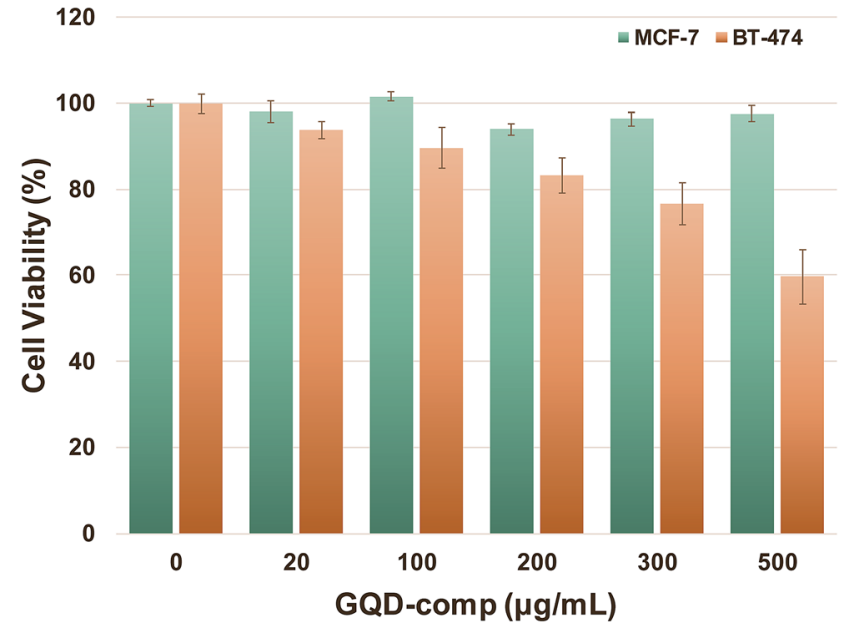

Fig. 3 The viability of MCF-7 and BT-474 cells incubated with GQDcomp for $48 \mathrm{~h}$ determined by $\mathrm{CCK}-8$ assay. Data are presented as the average $\pm \operatorname{SD}(n=5)$.

selective targeting property of GQD-comp. These in vitro results suggest not only good biocompatibility of GQD-comp, but also enhanced active targeting efficiency against HER2-positive breast cancer.

\subsection{Loading of DOX and $\mathrm{pH}-/$ temperature-triggered release of DOX from DL-GQD}

The resulting GQD-comp was evaluated as a tumor-targeting drug delivery nanocarrier with a $\mathrm{pH}$-responsive controlled release of drugs. DOX, a poorly water-soluble anticancer drug, was loaded into the hydrophobic cavity of $\beta$-CD via host-guest chemistry. Excess free DOX was removed by dialysis against DW for $20 \mathrm{~h}$. UV/Vis measurements were conducted to determine the LC and EE of DOX in the resulting DL-GQD. An extinction coefficient ( $\varepsilon=12800 \mathrm{M}^{-1} \mathrm{~cm}^{-1}$ ) was first obtained from a calibration curve of a series of DOX concentrations in the mixture of $\mathrm{DW} / \mathrm{DMF}=1 / 3(\mathrm{v} / \mathrm{v})$ at $\lambda_{\max }=496 \mathrm{~nm}$ (Fig. S3a $\dagger$ ). Using the Beer-Lambert equation, the LC and EE of DOX in DLGQD was determined to be $5.3 \pm 0.2 \%$ and $53.2 \pm 3.2 \%$ at the initial ratio of DOX/GQD-comp $=1 / 10 \mathrm{wt} / \mathrm{wt}$ (Fig. S3b $\dagger$ ). Considering the content of $\beta$-CD in GQD-comp (36 wt $\%$ determined by TGA), the LC of DOX in DL-GQD was determined to be around $15 \%$. Increasing the content of $\beta$-CD in GQD-comp can enhance the LC in DL-GQD. ${ }^{48}$

Controlled and rapid release of drugs is essential to achieve successful applications of drug delivery systems. To mimic lysosomal and physiological conditions of tumor tissues, the DOX release profile of DL-GQD was evaluated under different $\mathrm{pH}(5.5$ and 7.4$)$ at $37{ }^{\circ} \mathrm{C}$. As shown in Fig. 4 , about $70 \%$ of DOX was released from DL-GQD at pH 5.5, while only $20 \%$ of DOX was released at $\mathrm{pH} 7.4$ within $28 \mathrm{~h}$. Interestingly, this drug nanocarriers also showed a controlled release profile in response to temperature. When the temperature was raised from 25 to $37{ }^{\circ} \mathrm{C}$ at $\mathrm{pH} 5.5$, approximately $60 \%$ of cumulated DOX was increased within $28 \mathrm{~h}$. This dual stimuli-responsive drug release profile can be employed via two main 


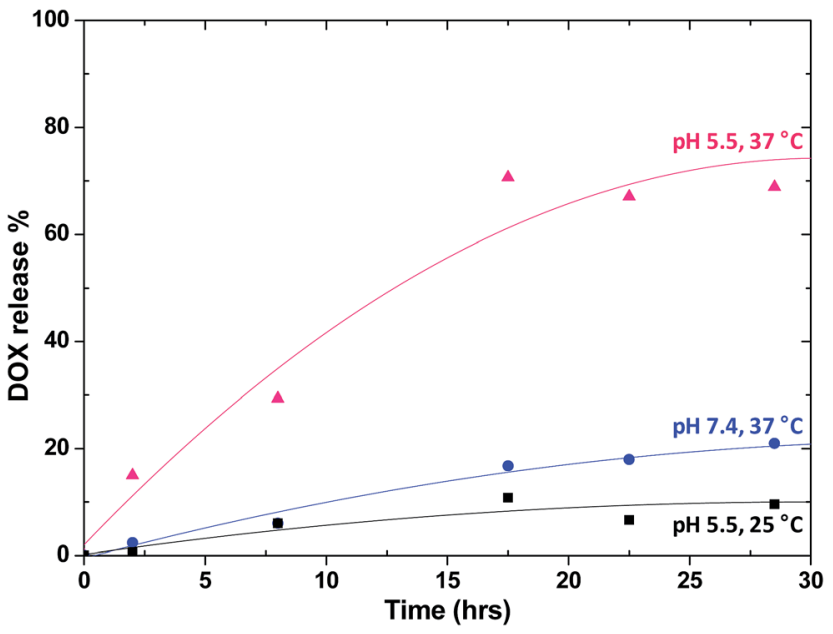

Fig. 4 In vitro release profile of DOX from DL-GQD in PBS under different conditions: $\mathrm{pH} 5$ at $37^{\circ} \mathrm{C}, \mathrm{pH} 7.4$ at $37^{\circ} \mathrm{C}$, and $\mathrm{pH} 5$ at $25^{\circ} \mathrm{C}$.

mechanisms. First, it is known that the formation of $\beta$-CD inclusion complexes with hydrophobic drugs is strongly affected by $\mathrm{pH}$ and temperature. ${ }^{49}$ In addition, hydrolysis of ester and amide bonds from GQD- $\beta$ CD and GQD-HER can be elevated by decreasing $\mathrm{pH}$ or increasing temperature. ${ }^{50}$ This remarkable result indicates the great potential of $\mathrm{pH}$ - and temperature-responsive GQD-comp as tumor-targeting drug carriers. These provide for a rapid and controlled release of anticancer therapeutics.

\subsection{Intracellular trafficking and bio-imaging efficiency}

Photoluminescence is one of the most important properties of GQDs in terms of how they are used as bio-imaging probes. ${ }^{51}$ Well-defined GQD-comp was evaluated as an effective tumortargeting diagnosis agent and a drug carrier. The intracellular uptake and distribution of GQD-comp and DOX-loaded GQDcomp (DL-GQD) in BT-474 cells was observed using CLSM

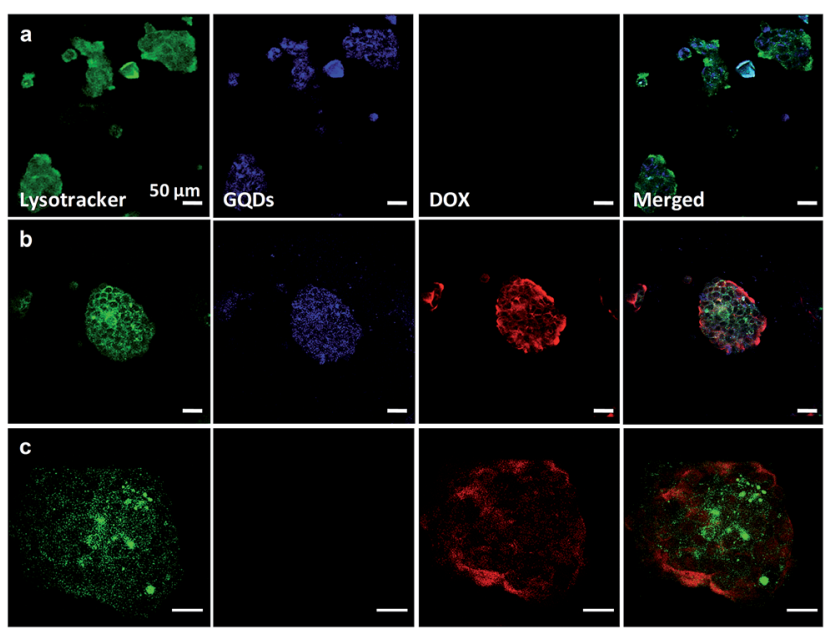

Fig. 5 CLSM images (scale bar $=50 \mu \mathrm{m}$ ) of BT-474 cells incubated with empty GQD-comp (a), DOX-loaded DL-GQD (b), and free DOX (c) for $14 \mathrm{~h}$.
(Fig. 5a and b). BT-474 cells were incubated with GQD-comp $\left(1 \mathrm{mg} \mathrm{mL}{ }^{-1}\right)$ and DL-GQD $\left(10 \mu \mathrm{gL}^{-1}\right)$ for $14 \mathrm{~h}$. The free DOX was designed to be the same amount of DOX in DL-GQD and it was also treated on BT-474 cells as a control (Fig. 5c). In order to avoid interference with the blue-color emitting GQDs, the lysosomes were selectively stained with Lysotracker dye, which showed a green color. After $14 \mathrm{~h}$ of incubation with GQD-comp, a strong blue signal was observed in BT-474 cells as compared with MCF-7 cells (Fig. S4†) and it was overlaid with the lysosome image. This indicated the successful internalization of GQD-comp in cytoplasm. When BT-474 cells were incubated with DL-GQD, a strong red-color signal, corresponding to the entrapped DOX in DL-GQD, was displayed in lysosomes and its intensity was comparable to that of free DOX. This also presented an effective intracellular uptake of DL-GQD. Interestingly, distributed DOX from DL-GQD and free DOX gave similar localization in the cell lysosome. This indicates that DOX was rapidly released from DL-GQD after cellular uptake. These CLSM results confirm that GQD-comp is a promising candidate to be used as an effective theranostic agent for HER2positive breast cancer treatment.

\subsection{In vitro apoptosis of DL-GQD}

Many researchers have reported that low anticancer activity of HER can be promoted when it is used along with chemotherapeutic agents such as DOX and paclitaxel. ${ }^{52}$ To determine the synergistic effect of dual delivery of HER and DOX, the in vitro cytotoxicity of DL-GQD was compared with free DOX using CCK8 assay. Cell viability results (Fig. 3) indicate that empty GQDcomp exhibited $>90 \%$ of BT-474 cell viability. This suggests a low anticancer activity of HER in GQD-comp even at doses up to $100 \mu \mathrm{g} \mathrm{mL} \mathrm{m}^{-1}$. However, the BT-474 cell viability significantly decreased with an increasing concentration of DL-GQD (Fig. 6). For example, when the BT-474 cells were incubated with DLGQD at $100 \mu \mathrm{g} \mathrm{mL} \mathrm{m}^{-1}$, the viability reduced to $<30 \%$. This significant decrease in BT-474 cell viability provides that DOX was effectively released from DL-GQD and inhibited the cellular

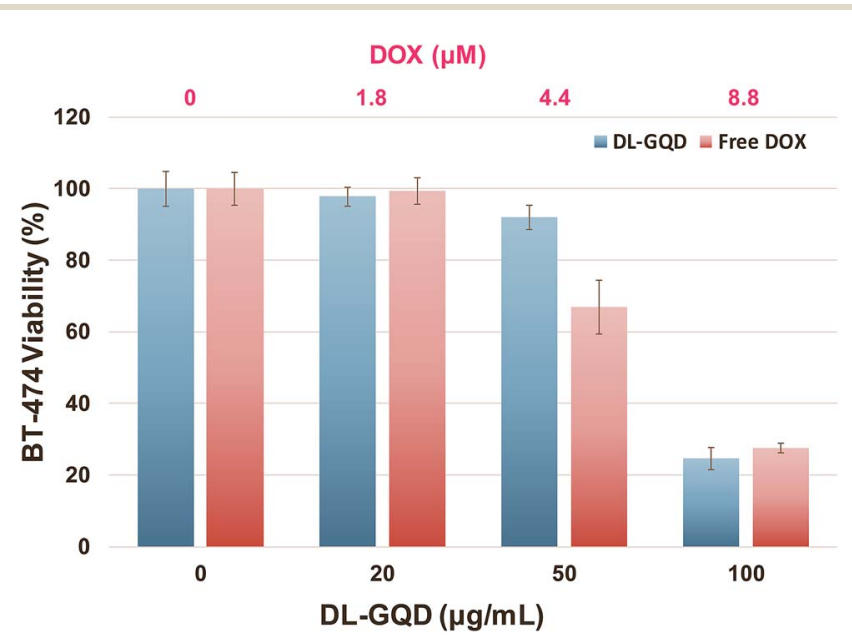

Fig. 6 The viability of BT-474 cells incubated with DL-GQD and free DOX for $48 \mathrm{~h}$ determined by CCK- 8 assay. Data are presented as the average \pm standard deviation $(n=5)$. 
proliferation of BT-474 cells, leading to successful apoptosis. As compared with DL-GQD, the viability of BT-474 incubated in the presence of free DOX gave lower values at the same concentrations. These results are consistent with other studies showing that the cellular uptake of free DOX occurs via a passive diffusion leading to higher cytotoxicity. However, the DOX-loaded nanocarriers were internalized into cells via endocytosis. ${ }^{53}$ These promising results from in vitro cytotoxicity confirmed not only that GQD-comp is an effective candidate for cancer-targeting drug delivery, but also that this combination strategy of HER and DOX can circumvent the low anticancer efficiency of HER. This system leads to a pronounced apoptosis of HER2overexpressed breast cancer.

\section{Conclusions}

In conclusion, novel HER-labeled GQD-based drug nanocarriers were designed for use as promising theranostic agents for targeting of HER2-overexpressed cancers. GQD-comp was synthesized via a facile coupling reaction and it can form an inclusion complex with DOX by the $\beta$-CD on the surface. The blue-color emission of GQD-comp enables the diagnosis of breast cancer and HER allows for effective, targeted accumulation in HER2overexpressed cancer cells. $\mathrm{pH}^{-}$and temperature-responsive release of DOX from DL-GQD inhibited the proliferation of cancer cells and this combination strategy of HER and DOX promoted the anticancer activity of DL-GQD. This multifunctional drug delivery system offers versatility in cancer targeting and enhanced drug delivery applications.

\section{Acknowledgements}

This research was supported by the Technology Innovation Program (No. 10054687) funded by the Ministry of Trade, Industry and Energy (MOTIE, Korea), Basic Science Research Program through the National Research Foundation of Korea (NRF) funded by the Ministry of Education (NRF2016R1A6A3A11934989), and the Public welfare \& Safety research program through the National Research Foundation of Korea (NRF) funded by the Ministry of Education, Science and Technology (NRF-2015R1D1A1A09060567).

\section{References}

1 A. K. Geim, Science, 2009, 324, 1530-1534.

2 S. N. Baker and G. A. Baker, Angew. Chem., Int. Ed., 2010, 49, 6726-6744.

3 J. Shen, Y. Zhu, X. Yang and C. Li, Chem. Commun., 2012, 48, 3686-3699.

4 X. Wang, X. Sun, J. Lao, H. He, T. Cheng, M. Wang, S. Wang and F. Huang, Colloids Surf., B, 2014, 122, 638-644.

5 X. Wang, X. Sun, H. He, H. Yang, J. Lao, Y. Song, Y. Xia, H. Xu, X. Zhang and F. Huang, J. Mater. Chem. B, 2015, 3, 3583-3590.

6 Z. Khatun, M. Nurunnabi, M. Nafiujjaman, G. R. Reeck, H. A. Khan, K. J. Cho and Y.-k. Lee, Nanoscale, 2015, 7, 10680-10689.
7 X. Tu, L. Wang, Y. Cao, Y. Ma, H. Shen, M. Zhang and Z. Zhang, Carbon, 2016, 97, 35-44.

8 P. Kalluru, R. Vankayala, C.-S. Chiang and K. C. Hwang, Biomaterials, 2016, 95, 1-10.

9 K. Habiba, J. Encarnacion-Rosado, K. Garcia-Pabon, J. C. Villalobos-Santos, V. I. Makarov, J. A. Avalos, B. R. Weiner and G. Morell, Int. J. Nanomed., 2016, 11, 107.

10 J. Peng, W. Gao, B. K. Gupta, Z. Liu, R. Romero-Aburto, L. Ge, L. Song, L. B. Alemany, X. Zhan, G. Gao, S. A. Vithayathil, B. A. Kaipparettu, A. A. Marti, T. Hayashi, J.-J. Zhu and P. M. Ajayan, Nano Lett., 2012, 12, 844-849.

11 A. Bianco, Angew. Chem., Int. Ed., 2013, 52, 4986-4997.

12 Z. Qian, J. Ma, X. Shan, L. Shao, J. Zhou, J. Chen and H. Feng, RSC Adv., 2013, 3, 14571-14579.

13 H. Chen, Z. Wang, S. Zong, P. Chen, D. Zhu, L. Wu and Y. Cui, Nanoscale, 2015, 7, 15477-15486.

14 L. A. Torre, F. Bray, R. L. Siegel, J. Ferlay, J. Lortet-Tieulent and A. Jemal, Ca-Cancer J. Clin., 2015, 65, 87-108.

15 A. Davidson, S. Chia, R. Olson, A. Nichol, C. Speers, A. J. Coldman, C. Bajdik, R. Woods and S. Tyldesley, CMAJ Open, 2013, 1, E134.

16 M. Kissin, G. Q. Della Rovere, D. Easton and G. Westbury, Br. J. Surg., 1986, 73, 580-584.

17 E. Paci, A. Cariddi, A. Barchielli, S. Bianchi, G. Cardona, V. Distante, D. Giorgi, P. Pacini, M. Zappa and M. R. Del Turco, Tumori, 1995, 82, 321-324.

18 S. H. Kim, B. H. Son, S. Y. Hwang, W. Han, J.-H. Yang, S. Lee and Y. H. Yun, J. Pain Symptom Manage., 2008, 35, 644-655.

19 B. Hoang, S. N. Ekdawi, R. M. Reilly and C. Allen, Mol. Pharm., 2013, 10, 4229-4241.

20 J. S. Ross, E. A. Slodkowska, W. F. Symmans, L. Pusztai, P. M. Ravdin and G. N. Hortobagyi, Oncologist, 2009, 14, 320-368.

21 I. Genentech, FDA advisory committee recommends approval of first monoclonal antibody for metastatic breast cancer, Media Release, 1998.

22 N. S. Karan, A. M. Keller, S. Sampat, O. Roslyak, A. Arefin, C. J. Hanson, J. L. Casson, A. Desireddy, Y. Ghosh, A. Piryatinski, R. Iyer, H. Htoon, A. V. Malko and J. A. Hollingsworth, Chem. Sci., 2015, 6, 2224-2236.

23 Y. Izumi, L. Xu, E. di Tomaso, D. Fukumura and R. K. Jain, Nature, 2002, 416, 279-280.

24 G. Bianchini and L. Gianni, Lancet Oncol., 2014, 15, e58-e68. 25 S. M. Tolaney, W. T. Barry, C. T. Dang, D. A. Yardley, B. Moy, P. K. Marcom, K. S. Albain, H. S. Rugo, M. Ellis, I. Shapira, A. C. Wolff, L. A. Carey, B. A. Overmoyer, A. H. Partridge, H. Guo, C. A. Hudis, I. E. Krop, H. J. Burstein and E. P. Winer, N. Engl. J. Med., 2015, 372, 134-141.

26 X. Wu, F. Tian, W. Wang, J. Chen, M. Wu and J. X. Zhao, J. Mater. Chem. C, 2013, 1, 4676-4684.

27 M. M. Bradford, Anal. Biochem., 1976, 72, 248-254.

28 T. Faltus, J. Yuan, B. Zimmer, A. Kramer, S. Loibl, M. Kaufmann and K. Strebhardt, Neoplasia, 2004, 6, 786795.

29 J. Baumann, C. Karch, A. Kourtidis and D. S. Conklin, Breast Cancer - Recent Advances in Biology, Imaging and Therapeutics, 2012, 17-36. 
30 S. Wang, Z.-G. Chen, I. Cole and Q. Li, Carbon, 2015, 82, 304313.

31 M. Nurunnabi, Z. Khatun, G. R. Reeck, D. Y. Lee and Y.-k. Lee, Chem. Commun., 2013, 49, 5079-5081.

32 Y. Dong, J. Shao, C. Chen, H. Li, R. Wang, Y. Chi, X. Lin and G. Chen, Carbon, 2012, 50, 4738-4743.

33 L. Tang, R. Ji, X. Cao, J. Lin, H. Jiang, X. Li, K. S. Teng, C. M. Luk, S. Zeng and J. Hao, ACS Nano, 2012, 6, 5102-5110.

34 D. N. Heo, W.-K. Ko, H.-J. Moon, H.-J. Kim, S. J. Lee, J. B. Lee, M. S. Bae, J.-K. Yi, Y.-S. Hwang and J. B. Bang, ACS Nano, 2014, 8, 12049-12062.

35 Y. Chong, Y. Ma, H. Shen, X. Tu, X. Zhou, J. Xu, J. Dai, S. Fan and Z. Zhang, Biomaterials, 2014, 35, 5041-5048.

36 Y. Liu, Y. Liu, S.-J. Park, Y. Zhang, T. Kim, S. Chae, M. Park and H.-Y. Kim, J. Mater. Chem. A, 2015, 3, 17747-17754.

37 M. Zheng, S. Liu, J. Li, Z. Xie, D. Qu, X. Miao, X. Jing, Z. Sun and H. Fan, J. Mater. Res., 2015, 30, 3386-3393.

38 J. Jeyasree, S. Jenifer, S. Priya, V. Sukumaran and D. K. Laveena, 2014.

39 J. Gu, M. Hu, Q. Guo, Z. Ding, X. Sun and J. Yang, RSC Adv., 2014, 4, 50141-50144.

40 L. R. Teixeira, R. D. Sinisterra, R. P. Vieira, M. C. Doretto and H. Beraldo, J. Inclusion Phenom. Macrocyclic Chem., 2003, 47, 77-82.

41 S.-J. Han, P. Rathinaraj, S.-Y. Park, Y. K. Kim, J. H. Lee, I.-K. Kang, J.-S. Moon and J. G. Winiarz, BioMed Res. Int., 2014, 2014, 954307.
42 P. Rathinaraj, A. M. Al-Jumaily and D. S. Huh, Breast Cancer: Targets Ther., 2015, 7, 51-58.

43 F. Bouchal, M. Skiba, N. Chaffai, F. Hallouard, S. Fatmi and M. Lahiani-Skiba, Int. J. Pharm., 2015, 478, 625-632.

44 Y. H. Bae and K. Park, J. Controlled Release, 2011, 153, 198205.

45 R. Nahta, D. Yu, M.-C. Hung, G. N. Hortobagyi and F. J. Esteva, Nat. Clin. Pract. Oncol., 2006, 3, 269-280.

46 Y. Mi, J. Zhao and S.-S. Feng, J. Controlled Release, 2013, 169, 185-192.

47 E. L. Sievers and P. D. Senter, Annu. Rev. Med., 2013, 64, 1529.

48 J. L. Manasco, C. Tang, N. A. Burns, C. D. Saquing and S. A. Khan, RSC Adv., 2014, 4, 13274-13279.

49 V. J. Stella, V. M. Rao, E. A. Zannou and V. Zia, Adv. Drug Delivery Rev., 1999, 36, 3-16.

50 P. Duan, L. Dai and P. E. Savage, J. Supercrit. Fluids, 2010, 51, 362-368.

51 F. Pinaud, X. Michalet, L. A. Bentolila, J. M. Tsay, S. Doose, J. J. Li, G. Iyer and S. Weiss, Biomaterials, 2006, 27, 16791687.

52 C. Rebischung, R. Barnoud, L. Stéfani, J.-L. Faucheron and M. Mousseau, Gastric Cancer, 2005, 8, 249-252.

53 L. Zhu, C. Tu, B. Zhu, Y. Su, Y. Pang, D. Yan, J. Wu and X. Zhu, Poly. Chem., 2011, 2, 1761-1768. 